\title{
COVID-19's Shock on Firms' Liquidity and Bankruptcy: Evidence from the Great Recession
}

Matthew Famiglietti, Research Associate

Fernando Leibovici, Economist

T he COVID-19 pandemic has been increasingly shutting down the U.S. economy. One concern is that this shock to the U.S. and global economies, which will likely be transitory, might have significant long-run economic effects.

While the revenues of firms in several sectors appear to be vanishing, these firms nevertheless remain committed to incurring large expenditures such as salaries and overhead costs, among other types of financial commitments firms typically face during normal times. Firms with large holdings of cash or fluid access to external finance are likely ready to face such commitments. However, firms with low liquidity and high debt might have limited access to external finance, making them vulnerable to sharp but transitory declines in revenues. These firms might eventually be forced into bankruptcy as a result of their inability to cover their short-term liabilities.

In this essay we investigate the extent to which the COVID-19 pandemic's shock to firms' liquidity might lead financially vulnerable firms to close down. Given the ongoing nature of the pandemic, we rely on evidence from the Great Recession of 2008-09 to study the potential long-run effects of the COVID-19 pandemic on U.S. firms.

As the pandemic continues, financially vulnerable firms might be at greater risk of closing.

Our starting point is the observation that U.S. nonfinancial firms currently hold historically very high levels of short-term debt. Figure 1 plots the evolution over time of short-term debt as a share of GDP, showing that the COVID-19 pandemic is hitting U.S. firms with short-term financial commitments at levels close to those at the peak of the Great Recession.

The COVID-19 pandemic is, thus, affecting U.S. firms in an economic environment in which many of them are likely to be financially vulnerable. But COVID-19 is not

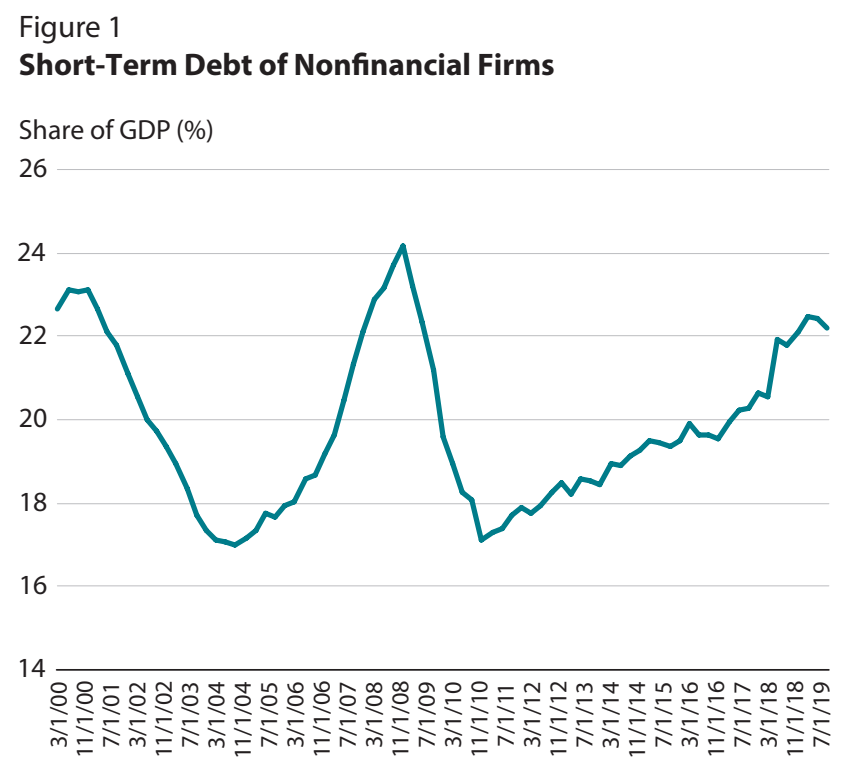

SOURCE: Board of Governors of the Federal Reserve System and Bureau of Economic Analysis. Debt measures are obtained through the Federal Reserve Board's Flow of Funds database.

only leading to a decline in revenues in several sectors; it also appears to be tightening firms' access to external finance. This is indeed what the Office of Financial Research's Financial Stress Index suggests, as illustrated in Figure 2. This index is published daily and captures a snapshot of current financial market conditions. ${ }^{1}$ In recent days, this measure has spiked to levels of stress not experienced since the Great Recession or the dot-com bubble. This implies that COVID-19 is having a significant impact on financial markets.

To what extent might stress in financial markets have long-run consequences for financially vulnerable firms in the U.S.? We address this question by examining the extent to which financially vulnerable firms were forced to close down in response to the liquidity shock firms faced during the Great Recession of 2008-09.

We use the National Establishment Time Series database collected by Dun \& Bradstreet, which provides detailed 
Figure 2

\section{Financial Stress}

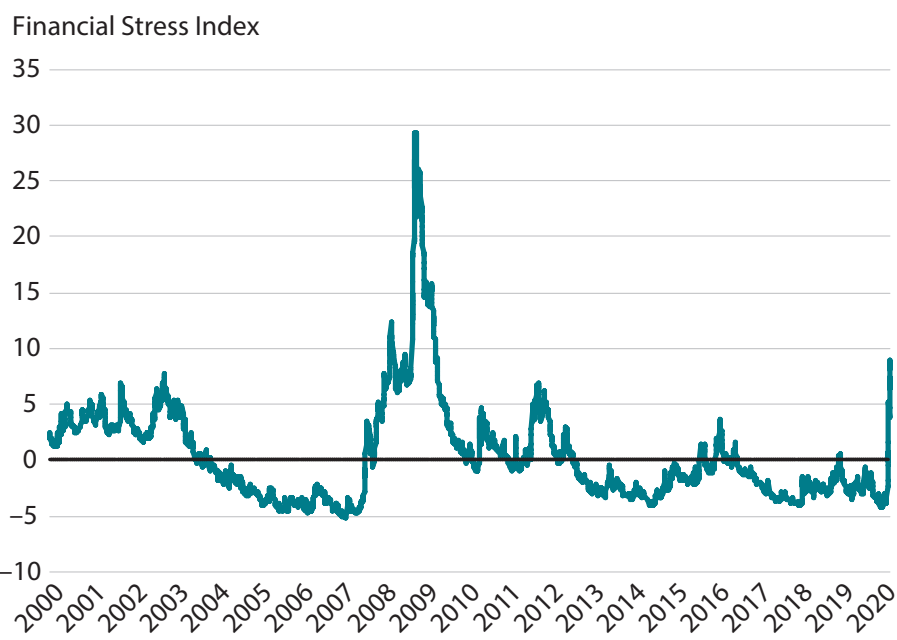

SOURCE: The Financial Stress Index is a measure of the Office of Financial Research, an independent bureau within the U.S. Department of the Treasury. The index takes into account current credit conditions, equity valuations, access to funding, value of safe assets, and market volatility.

data on the ratings of U.S. nonfinancial firms in their trade credit transactions-that is, their firm-to-firm financial operations. The ratings reflect the timeliness of firms' trade credit payments. We refer to firms that pay off their trade credit liabilities more than 30 days late as "delinquent" (6.4 percent of all firms, on average).

Figure 3 plots the exit rates of firms during the Great Recession based on their trade credit rating in 2007 at the onset of the Great Recession. We interpret differences in firms' trade credit ratings at the onset of the Recession as an indicator of financial vulnerability, with firms that were delinquent at the onset of the Recession being more financially vulnerable than their counterparts in good standing. We observe that delinquent firms were significantly more likely to close down during the Great Recession than firms that were initially in good standing; that is, financially stressed firms in a high-debt environment were less able to pay off short-term debt and more likely to close down.
Figure 3

\section{Exit Rates during the Great Recession}

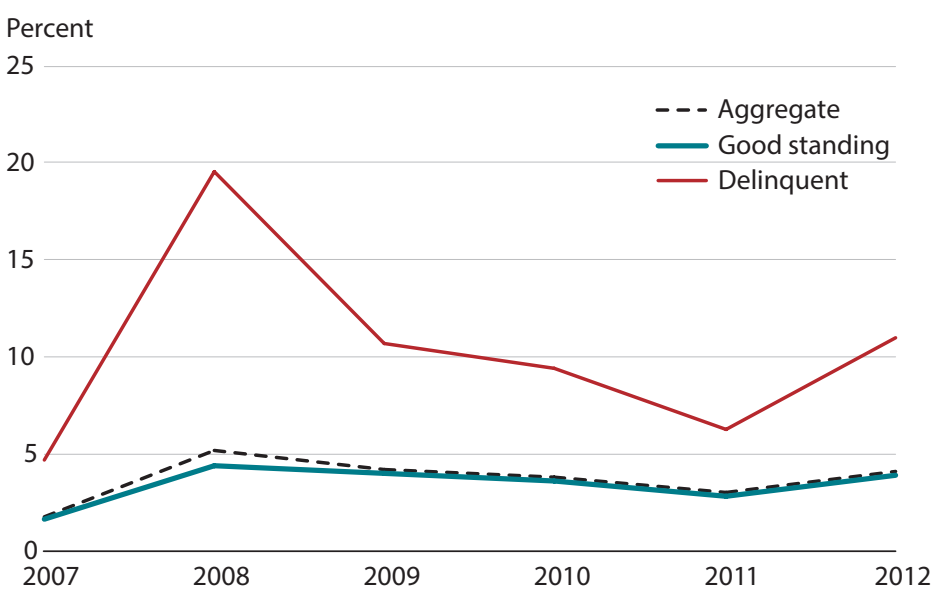

SOURCE: National Establishment Time Series database collected by Dun \& Bradstreet. We use all firms in the database with credit ratings and at least 10 employees to compute the figure.

These findings suggest that, as the COVID-19 pandemic continues, financially vulnerable firms might be increasingly pushed to close down. The pandemic will likely be transitory, but its impact on U.S. firms could persist over time unless policies are put in place to alleviate firms' limited access to liquidity.

\section{Note}

1 The Office of Financial Research Financial Stress Index (OFR FSI) is a daily market-based snapshot of stress in global financial markets. It is constructed from 33 financial market variables, such as yield spreads, valuation measures, and interest rates. The OFR FSI is positive when stress levels are above average, and negative when stress levels are below average. 